\title{
Successful digital cholangioscopy removal of a stent-retriever tip migrated into the periphery of the bile duct
}

Various techniques to dilate occluded uncovered metal stents (UMSs) have been reported [1]. A stent retriever (Soehendra stent retriever, SSR-7; Cook, Tokyo, Japan) can also be used as a dilation device in endoscopic retrograde cholangiopancreatography (ERCP) [2,3]. Herein, we describe a case in which the tip of a stent retriever migrated into the periphery of the bile duct and was successfully removed using digital cholangioscopy.

An 85-year-old man had undergone placement of multiple UMSs for hepatic hilar biliary stricture 1 year previously. Since the stent placement, re-intervention had been performed three times because of stent occlusion; however, he was admitted to our hospital because of a recurrence of obstructive jaundice. Computed tomography (CT) scanning showed anterior bile duct dilatation, and re-intervention was attempted.

First, the guidewire was placed into the anterior bile duct. Neither an ERCP catheter nor a balloon catheter could be advanced into the anterior bile duct through the mesh of the UMS, so recanalization using a stent retriever was

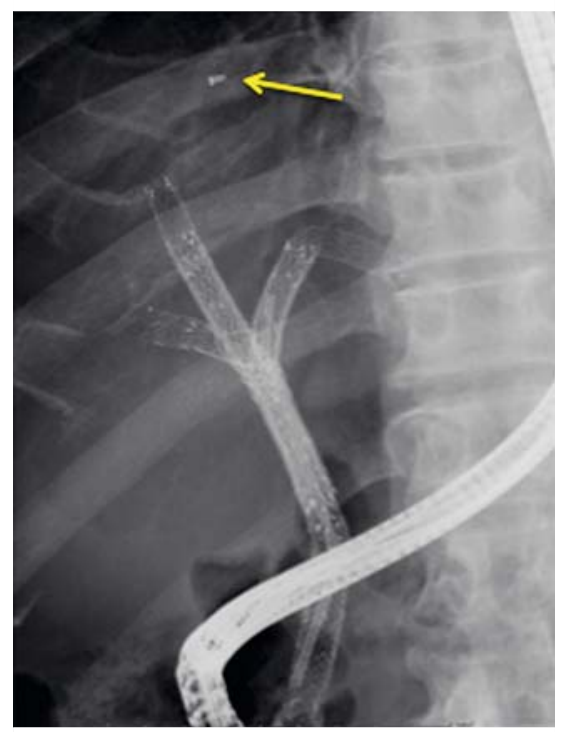

- Fig. 1 Radiographic image showing the migrated tip of the Soehendra stent retriever (arrow) in the periphery of the bile duct.

attempted. However, during this procedure, the tip of the stent retriever became detached and migrated into the periphery of the bile duct ( $\triangleright$ Fig. 1 ). To remove this migrated stent-retriever tip, several techniques including the use of biopsy

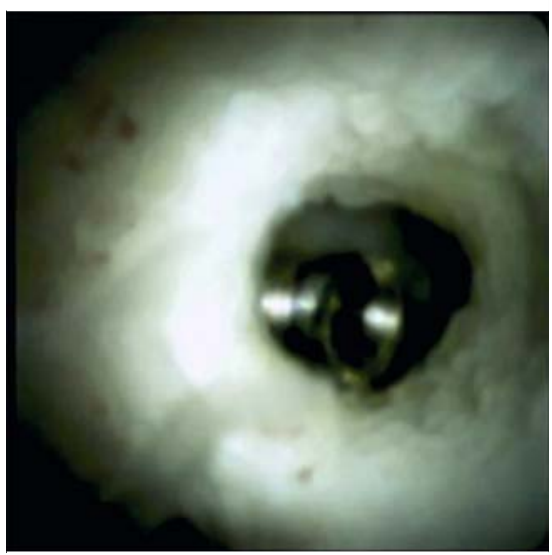

> Fig. 2 Cholangioscopic view showing the tip of the stent retriever using a digital intraductal cholangioscope (SPY-DS).

forceps, basket catheter, and balloon catheter were performed, but without successful removal being achieved.

Removal under direct visualization was therefore attempted using a digital single-operator intraductal cholangioscope (IDC; SPY-DS; Boston Scientific). The cholangioscope was advanced into the periphery of the anterior bile duct through the UMS until the migrated tip of the stent retriever could be seen
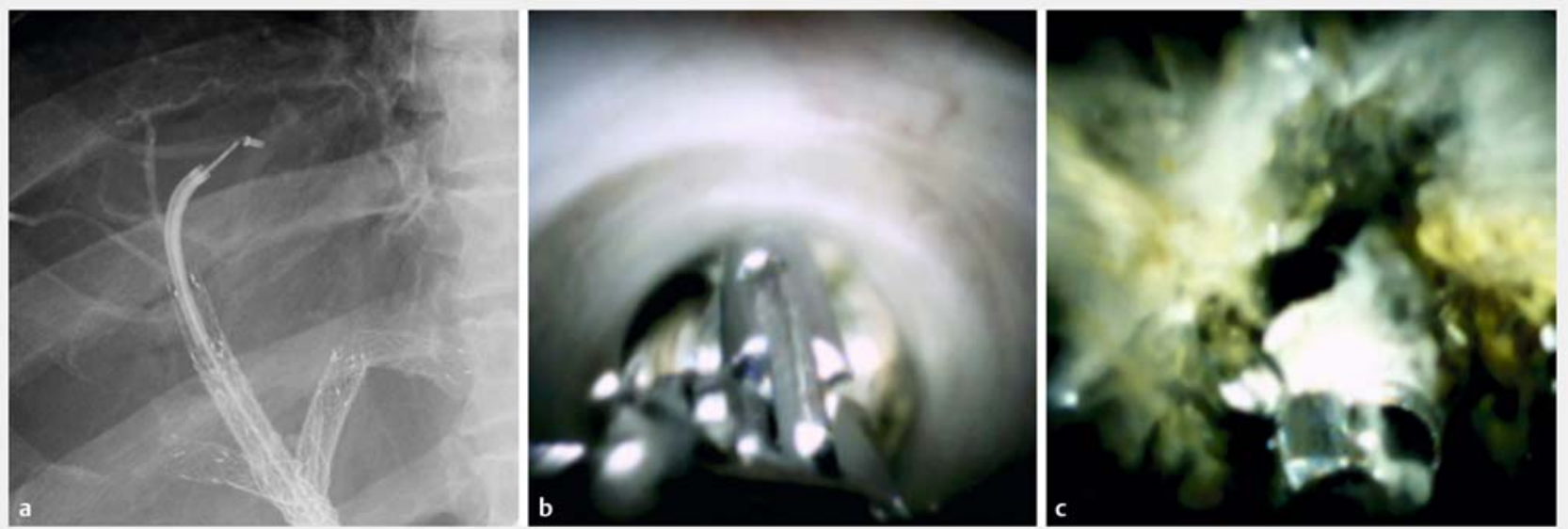

Fig. 3 The tip of the stent retriever is grasped using the SPY-Bite device: $\mathbf{a}$ on radiographic image; $\mathbf{b}$ on cholangioscopic image; and $\mathbf{c}$ is carefully removed. 


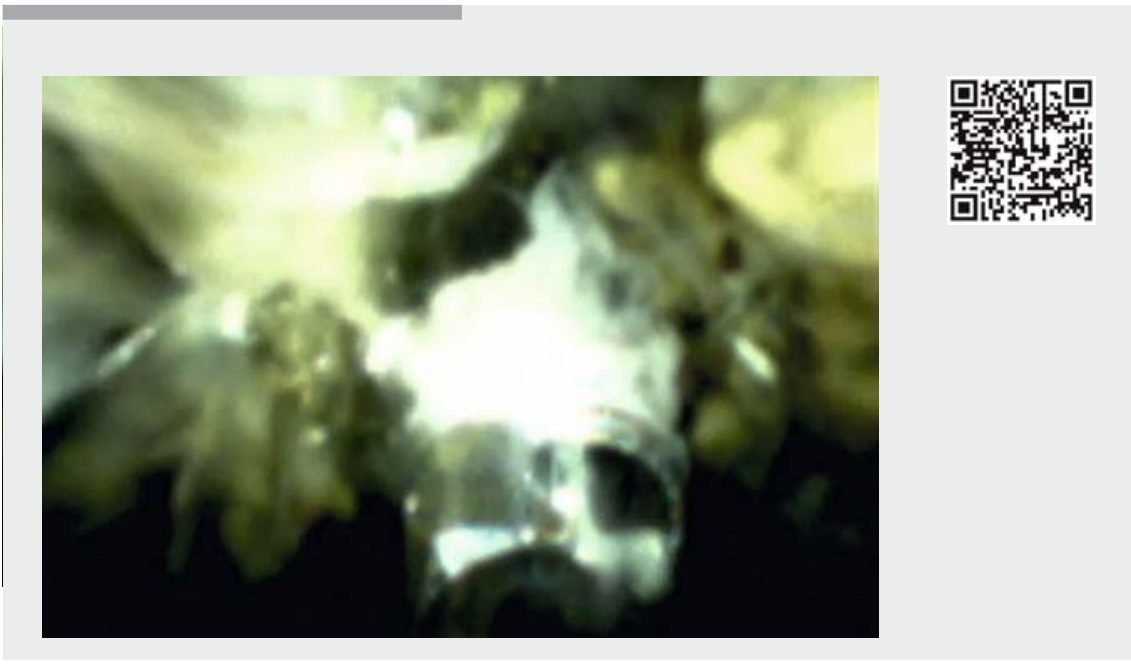

$\checkmark$ Video 1 The intraductal cholangioscope (SPY-DS) is inserted into the periphery of the bile duct through the uncovered metal stents and the migrated tip of the stent retriever is observed. The migrated tip is then grasped by the SPY-Bite device under direct visualization, allowing it to be successfully removed.

( $\triangleright$ Fig. 2; $\triangleright$ Video 1 ). Next, the migrated tip was grasped by a SPY-Bite device ( Fig.3a,b). The cholangioscope was then itself carefully withdrawn from the bile duct into the intestine ( $\triangleright$ Fig.3c), successfully removing the migrated tip without any adverse events ( $>$ Fig. 4 ).

In conclusion, this case may be the first to show this adverse event associated with a stent retriever, along with the subsequent successful removal. Direct visualization with the digital IDC was helpful in this case.

Endoscopy_UCTN_Code_CPL_1AK_2AD

\section{Competing interests}

None

The authors

Takeshi Ogura, Atsushi Okuda, Akira Miyano, Nobu Nishioka, Kazuhide Higuchi

2nd Department of Internal Medicine, Osaka Medical College, Osaka, Japan

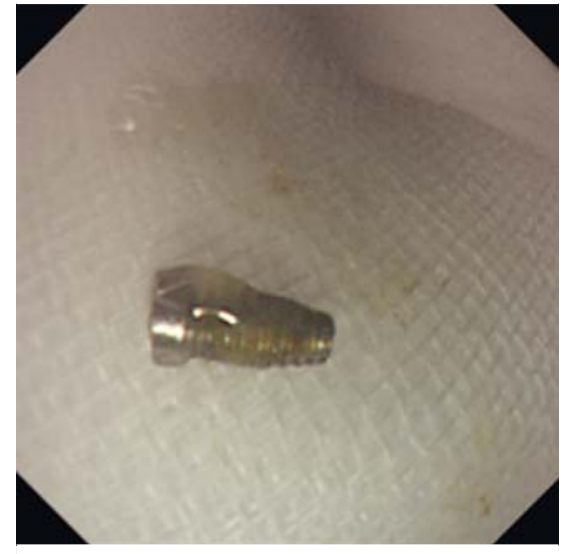

Fig. 4 The tip of the stent retriever following its successful removal.

\section{Bibliography}

DOI https://doi.org/10.1055/s-0044-101019

Published online: 16.2.2018

\section{Takeshi Ogura, MD}

2nd Department of Internal Medicine, Osaka Medical College, 2-7 Daigakuchou, Takatsukishi, Osaka 569-8686, Japan Fax: +81-726-846532

oguratakeshi0411@yahoo.co.jp

\section{References}

[1] Kawakami H, Itoi T, Kuwatani M et al. Technical tips and troubleshooting of endoscopic biliary drainage for unresectable malignant hilar biliary obstruction. J Hepatobiliary Pancreat Sci 2015; 22: E12-E21

[2] Inoue T, Yamamoto T, Ishii $\mathrm{N}$ et al. Doubleballoon enteroscopy-assisted ERCP in situs inversus with Roux-en-Y hepaticojejunostomy for complex anastomotic stricture dilated with Soehendra stent retriever. Endoscopy 2017; 49: E46-E47

[3] Mohamed E, Kröner PT, Kumar U et al. Use of a Soehendra stent retriever in dilation of an anastomotic biliary stricture in a post-liver transplant patient. Endoscopy 2016; 48: E35-E36
Endoscopy 2018; 50: E113-E114

(c) Georg Thieme Verlag KG

Stuttgart · New York

ISSN 0013-726X

\section{ENDOSCOPY E-VIDEOS}

https://eref.thieme.de/e-videos

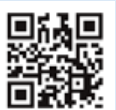

Endoscopy E-Videos is a free access online section, reporting on interesting cases and new techniques in gastroenterological endoscopy. All papers include a high quality video and all contributions are freely accessible online.

This section has its own submission website at

https://mc.manuscriptcentral.com/e-videos 